\title{
ARTIGO
}

DOI: https://doi.org/10.22481/praxis.v15i31.4667

\section{ESCRITA LITERÁRIA: DESAFIOS E POSSIBILIDADES}

\author{
LITERARY WRITING: CHALLENGES AND POSSIBILITIES
}

ESCRITURA LITERARIA: DESAFÍOS Y POSIBILIDADES

\author{
Andreia dos Santos Oliveira \\ Instituto Federal de Rondônia - Brasil \\ Cyntia Graziella Guizelim Simões Girotto \\ Universidade Estadual Paulista - Brasil \\ Juracy Machado Pacífico \\ Universidade Federal de Rondônia - Brasil
}

\begin{abstract}
Resumo: Trata-se do projeto de ensino "Escrita literária: desafios e possibilidades" desenvolvido com alunos dos primeiros anos dos cursos técnicos integrados ao Ensino Médio do Instituto Federal de Rondônia. As ações partiram da seguinte problematização: Como despertar o interesse dos alunos pelo texto literário e motivá-los a escrever textos diferentes daqueles usuais da área escolhida? Para isso delineou-se como objetivo criar ambiente favorável à leitura e escrita literária em que os discentes sintam-se sujeitos do processo. Na condução das ações, utilizamos os postulados de Fiorin e Savioli (2006) por defenderem a escrita literária como possibilidade de recriação do mundo, de Antunes (2003) que nos apresentou as várias etapas interdependentes e intercomplementares envolvidas na criação do texto literário, e na teoria Histórico-cultural de Vygotski (1995) que defende o uso da escrita a partir de uma necessidade do sujeito. Como eixos de ação, elaboramos situações em que os alunos tiveram contato com a leitura de textos literários, atuando como críticos do processo de composição textual, em seguida o planejamento da obra, revisão e reescrita. Como resultado tem-se que os alunos deixaram de ser leitores e escritores passivos e tornaram-se sujeitos da ação ao verem função no ato de escrever.
\end{abstract}

Palavras-chave: Educação. Escrita literária. Teoria histórico-cultural.

\begin{abstract}
Thisproject "Literarywriting: challengesandpossibilities" wasdevelopedbyhigh school students from integrated course of Instituto Federal de Rondônia. Actions started from this problematization: How can students' interests be aroused and motivate them to write texts so different from those that are habitual to the chosen area? For this, it outlined as goal criate environment favorable to reading and writing. To condute this actions, we use the postulates from Fiorin and Savioli (2006) because they defend literary writing as possibility of recreation of world, from Antunes (2003) who introduced us the various phases interdependent and intercomplementary involved in the elaboration of the literary text, and in historical theory cultural from Vygotski (1995) who defend the use of the writing from a need of the subject. As axes of action, we elaborated situations who the high school student had contact with the reading of the literary texts, as they were critical of the process of writing textual, after this, they planned the book, they revised and rewrote. As a result, it has been found that high school students have ceased to be passive readers and writers and became subjects of the action when they saw function in the act of writing.
\end{abstract}


Keywords: Education. Historical-cultural theory. Literarywriting.

Resumen: Se trata del proyecto de enseñanza "Escritura literaria: desafíos y posibilidades" desarrollado con alumnos de los primeros años de los cursos técnicos integrados a la Enseñanza Media del Instituto Federal de Rondônia. Las acciones partieron de la siguiente problematización: ¿Cómo despertar el interés de los alumnos por el texto literario y motivarlos a escribir textos diferentes de aquellos usuales del área escogida? Para ello se delineó como objetivo crear ambiente favorable a la lectura y escritura literaria en que los discentes se sienten sujetos del proceso. En la conducción de las acciones, utilizamos los postulados de Fiorin y Savioli (2006) por defender la escritura literaria como posibilidad de recreación del mundo, de Antunes (2003) que nos presentó las varias etapas interdependientes e intercomplementarias involucradas en la creación del texto literario, y en la teoría Historia-cultural de Vygotski (1995) que defienden el uso de la escritura a partir de una necesidad del sujeto. Como ejes de acción, elaboramos situaciones en que los alumnos tuvieron contacto con la lectura de textos literarios, actuando como críticos del proceso de composición textual, luego la planificación de la obra, revisión y reescritura. Como resultado se tiene que los alumnos dejaron de ser lectores y escritores pasivos y se volvieron sujetos de la acción al ver la función en el acto de escribir.

Palavras clave: Educación. Escritura literária. Teoría historico-cultural.

\section{Introdução}

É por possuir essa função maior de tornar o mundo compreensível transformando sua materialidade em palavras de cores, odores, saberes e formas intensamente humanas que a literatura tem e precisa manter um lugar especial nas escolas. (COSSON, 2011, p. 5).

A epígrafe já assinala o ponto principal desse artigo, que apresenta um relato de experiência vivenciada em turmas de primeiros anos dos cursos técnicos integrado de Agroecologia e Agropecuária do Instituto Federal de Rondônia, campus Cacoal. Trabalhar nesses cursos e criar condições capazes de despertar o gosto pela escrita literária sempre foi desafiador, haja vista tratar-se de uma modalidade de ensino que visa, sobretudo, preparar alunos para o mercado de trabalho, por isso muitas vezes no planejamento de nossas aulas acabamos nos esquecendo de conteúdos indispensáveis para o ser humano como é o caso da arte literária. A partir dessas inquietações, elaborou-se a seguinte questão problematizadora norteadora de toda a ação pedagógica desenvolvida em sala de aula: Como criar necessidades nos alunos pela escrita literária e motivá-los a escrever textos tão diferentes daqueles usuais da área escolhida? A partir disso a ação foi planejada com o objetivo de criar ambiente favorável à leitura e à escrita literária em que os discentes pudessem sentir-se sujeitos do processo durante a realização da atividade. O trabalho foi desenvolvido em sete momentos a 
saber: leituras, planejamento, escrita, revisão, reescrita, produção das imagens, impressão das obras.

Durante o projeto, os alunos, através da mediação, apropriaram-se dos elementos necessários à escrita literária e a tarefa deixou de ser mera ação pedagógica e transformou-se em atividade repleta de momentos de prazer, gostosuras, viagem, descobertas. Os alunos sentiram-se motivados e foram além do proposto, escreveram verdadeiras obras de arte. No escrito em pauta, inicialmente destacamos a importância da escrita no Ensino Médio e a partir daí propomos algumas reflexões específicas sobre a escrita literária. Por fim fazemos relato e discussão do projeto desenvolvido durante o ano de 2017.

\section{A importância da escrita no Ensino Médio}

Ler e escrever são atividades essenciais para o desenvolvimento da cognição humana, contribuindo assim para a inserção do indivíduo na sociedade letrada. Compreender a realidade em que estamos inseridos e conhecer as demais realidades existentes no mundo é apenas uma das muitas contribuições da leitura e escrita. Esses dois instrumentos são eficazes para uma compreensão mais global de tudo o que nos cerca.

Nessa perspectiva é atribuído à escola o papel de capacitar os alunos para a prática eficiente do ato de ler e escrever. Porém, avaliações de massa apontam a deficiência das instituições escolares em formar alunos eficientes leitores e escritores de sua própria língua.

Escrever é uma atividade complexa, pois segundo Vygotiski (apud SAVELLI, 2007), esta distingue-se do ato de falar, porque requer um elevado nível de abstração. Escrever é muito mais do que se comunicar por meio de signos linguísticos verbais, pois ultrapassa essa definição para tornar-se resultado de uma ação reflexiva (SAVELLI, 2007). Para escrever é preciso pensar nos objetivos, os possíveis interlocutores, o nível de linguagem mais adequada àquele texto, o gênero textual e o suporte mais indicado e ainda fazer escolhas linguísticas que contribuam para a eficiência do escrito.

A escola é um dos locais que tem como objetivo formar alunos que leiam e produzam os mais variados gêneros textuais que circulam na sociedade. Muitas vezes, entretanto, os textos são produzidos sem objetivos claros, tendo apenas o professor como leitor, contribuindo para que os alunos não vejam sentido no processo.

$\mathrm{Na}$ contemporaneidade, há incontáveis gêneros textuais em circulação. Alguns mais utilizados do que outros, dependendo do contexto social no qual o aluno está inserido. É 
função da escola e do professor mediador proporcionar o contato com estes distintos gêneros, apresentando suas funções e usos, haja vista serem resultados de um conhecimento cultural e social.

\section{A escrita literária}

A literatura, arte da palavra, é fundamental para a constituição do sujeito, pois esta forma de manifestação artística por meio de signos linguísticos contribui para o enriquecimento "linguístico, social e educacional" (GALVÃO, s/d, p. 1). Por tratar de temas inerentes ao ser humano, como atitudes, anseios, medos, alegrias e tantos outros sentimentos, pode-se afirmar que esse gênero textual contribui para a composição da identidade humana. Lendo obras literárias viajamos para lugares desconhecidos e encantados, sentimos raiva, alegria, medo, angústia e também nos deparamos com os distintos sentimentos humanos. Viajamos sem sair do lugar. E mesmo que este não seja seu objetivo principal, obtemos conhecimentos das mais distintas áreas do conhecimento. Ler permite o exercício da cidadania.

Isso pode ser observado durante a escrita literária pelos alunos do ensino técnico integrado, pois enquanto escreviam seus livros, solicitavam que outros discentes e professores da instituição lessem seus textos e, muitas vezes, os leitores mostravam-se indignados com os finais escolhidos para algumas histórias, tendo em vista que nem sempre os alunos-autores escolhiam finais felizes para seus textos. Muitos optaram por desfechos surpreendentes, criativos e tristes.

Outros alunos, ao terem contato com textos que dialogavam com outros, compreenderam essa característica como uma das características textuais e fizeram uma produção intertextual. Um dos alunos-autores produziu um texto narrando a história de um personagem que viajou para muitos países em busca de encontrar respostas para seus questionamentos, dúvidas e anseios. Para isso, precisou recorrer a outras línguas para utilizar dentro dos textos, a exemplo do Inglês e Espanhol.

Dominar as mais distintas formas de linguagem no mundo contemporâneo é elemento potencializador do desenvolvimento da escrita e essencial para a inserção do sujeito na cultura letrada. Essa ideia está pautada em Cosson $(2011$, p. 3) quando afirma: "Em uma sociedade letrada como a nossa, as possibilidades de exercício do corpo linguagem pelo uso são inumeráveis. Há, entretanto, uma que ocupa lugar central. Trata-se da escrita”. 
Catherine Tauveron (apud DALLA-BONA; BUFREM, 2013), criadora, em 1960, da expressão aluno-autor, afirmou que não é função da escola formar escritores, mas ao mesmo tempo, essa instituição não pode impedir a mediação professor-aluno-cultura. Para isso, faz-se necessário que o docente proporcione o contato dos alunos com diversos gêneros textuais para que eles compreendam as especificidades da linguagem literária:

O ser humano produz duas linguagens a partir de sua língua: uma racional, empírica, prática, técnica; outra simbólica, mítica, mágica. A primeira tende a precisar denotar, definir, apoiar-se sobre a lógica e ensaia objetivar o que ela mesma expressa. A segunda utiliza mais a conotação, a analogia, a metáfora, ou seja esse halo de significações que circunda cada palavra, cada enunciado e que ensaia traduzir a verdade da subjetividade. Essas duas linguagens podem ser justapostas ou misturadas, podem ser separadas, opostas, e cada uma delas correspondem dois estados. (MORIN, 1999, p. $35)$.

Muitos têm a visão errônea de que escrever literatura seja um dom e portanto não se justifica o trabalho com essa forma de escrita em sala de aula. Autores como Taveron (1996, apud DALLA-BONA; BUFREM, 2013) discordam dessa ideia e defendem a escola como instituição desenvolvedora dessa habilidade. Mas para isso, necessário se faz transformar a visão do aluno de leitor para escritor. Gonzales (2009 apud DALLA- BONA; BUFREM, 2013) elenca algumas atitudes que o professor deve propiciar ao aluno para que ele se veja como autor. São elas:

Ler como um autor. Espera-se que o autor conheça a fundo as obras com as quais seu trabalho tem relação, para tomar consciência do funcionamento do gênero como uma "máquina" expressiva da qual ele precisa descobrir os mecanismos;

Tomar decisões como autor, se situando no contexto de um gênero. A elaboração do plano da história é um dos momentos-chave para a aprendizagem da postura de autor. A partir desse plano, o aluno pode ser guiado pelas possibilidades do gênero literário escolhido e assumir de maneira criativa o papel de narrador;

Dialogar com outros autores. A classe é uma comunidade de autores, interlocutores e parceiros à disposição do aluno-autor para testar os efeitos do seu texto;

Escrever para os leitores. Os alunos devem levar em consideração o seu destinatário, pois um autor se constrói porque ele procura seu leitor. (GONZALES, 2009 apud DALLA-BONA; BUFREM, 2013, p. 4).

Estratégias como as descritas acima inserem o aluno no papel de autor, motivando-o para a criação de seu próprio texto, assumindo posturas e responsabilidades inerentes ao escritor. E foi baseada nelas que durante todo o ano de 2017, desenvolvemos condições em sala de aula para que os alunos vivenciassem o papel de escritor. 
A primeira condição diz respeito à leitura dos contos de Marina Colassanti "A moça tecelã" e "A primeira só", identificando primeiramente as características do texto narrativo, tais como: tipo de narrador, escolhas dos personagens, suas características, espaços físicos e psicológicos, a escolha do tempo (cronológica, psicológico) e o enredo. Em seguida, analisamos os marcadores temporais e escolhas linguísticas que fazem predominar a função poética nesses textos. O mesmo trabalho foi realizado com o conto Felicidade Clandestina de Clarice Lispector.

Após essa etapa, solicitamos que os alunos lessem as obras "O pequeno príncipe" de Antoine de Saint-Exupery (2009) e "O meu pé de laranja lima" (2005) do escritor José Mauro de Vasconcelos. A leitura deveria proporcionar um diálogo com os textos e fazer com que os alunos pensassem em como agiu o autor para produzir aquela obra literária. Após a leitura, criamos condições em sala de aula para exposição e discussão das obras lidas. Na ocasião os discentes expuseram suas considerações sobre as escolhas do autor, tais como personagens, enredo, foco narrativo e desfecho. Com isso, assumiram a posição de críticos literários.

Após a atividade de leitura há uma gama de atividades que podem ser desenvolvidas no intuito de ampliar o conhecimento dos alunos leitores, portanto além das discussões e análises promovidas em sala, tencionamos a produção de narrativas literárias: "a leitura literária pode expandir o seu lugar na escola através de múltiplas atividades, que permitam sua integração e conferência com outros tipos de aprendizados" (COLOMER, 2007, p. 21).

Tauveron (1999 apud DALLA-BONA; BUFREM, 2013) rebate a crença de que ler textos literários seja suficiente para formar escritores literários. Essas são, para ele, atividades distintas, mas complementares, pois escrever vai além de identificar as características. Requer incorporação de autor, e para isso faz-se necessário a elaboração da imagem de si mesmo com suas características individuais.

Segundo Dalla-Bona e Bufrem (2013), para compor seus textos literários os alunos baseiam-se prioritariamente nas obras já lidas por eles, mas deixam evidências de suas crenças e concepções, conforme afirma Cosson (2011, p. 5): "Na leitura e na escrita do texto literário encontramos o senso de nós mesmos e da comunidade a que pertencemos”.

Proporcionar situações para que os alunos desenvolvam competências da linguagem verbal escrita torna-se importante não apenas porque isso é fundamental para a inserção do indivíduo na sociedade letrada, mas, sobretudo, porque, segundo Cosson (2011, p.3), “A escrita é, assim, um dos mais poderosos instrumentos de libertação das limitações físicas do ser humano." Ao escrever, damos asas à imaginação e criamos personagens, lugares e 
situações inimagináveis, de modo que "No exercício da literatura, podemos ser outros, podemos viver como os outros, podemos romper os limites do tempo e do espaço de nossa experiência, e ainda assim, sermos nós mesmos". (COSSON, 2011, p. 5).

E é exatamente esse poder viver situações fantásticas e que ao mesmo tempo em que se assemelham tanto com nossas realidades também nos permitem viajar em distintas épocas, pelos mais inimagináveis espaços e realizar ações diversas é que o ato de escrever literatura se mostra como atividade criativa, prazerosa e recriadora da realidade. Para Cosson (2011, p.4): “[...] o corpo escrito encontra na literatura seu mais perfeito exercício. A literatura não apenas tem a palavra em sua constituição material, como também a escrita é seu veículo predominante".

Trabalhar com a escrita literária em sala de aula é possibilitar ao aluno desconstruir as regras impostas de linguagem culta formal e propiciar momentos de brincadeira e compreensão de que a língua não possui estrutura fixa e sim pode se encaixar em formas distintas para provocar reações inusitadas no leitor/receptor:

[...] é no exercício da leitura e escrita dos textos literários que se desvela a arbitrariedade das regras impostas pelos discursos padronizados da sociedade letrada e se constrói de um modo próprio de se fazer dono da linguagem que, sendo minha, é também de todos. (COSSON, 2011, p. 5).

Faz-se necessário que mesmo em um curso que visa formar técnicos para o mercado de trabalho, seja proporcionado situações que desvelem possíveis escritores, uma vez que o contato com a literatura é essencial ao ser humano.

E foi neste intuito, pensando em primar o ensino da literatura, tanto da leitura quanto da escrita que passamos à segunda etapa do projeto: o planejamento das narrativas literárias. Solicitamos que, em duplas, os alunos fizessem o planejamento de uma narrativa literária, levando em consideração elementos como: o público a quem a narrativa se destinava, a temática, os personagens principais, espaços e enredo, tipo de narrador. Definir o público, previamente à escrita foi indispensável, pois dessa forma o aluno-escritor pode pensar em questões como a temática mais adequada, a linguagem que deveria ser utilizada, entre outros. Para realizar esta etapa do projeto nos referenciamos em Dalla-Bona e Bufrem (2013, p. 3) que nos dizem: “[...] uma das primeiras particularidades a considerar é que um texto literário precisa ser concebido tendo em vista o seu potencial leitor”. 
De posse dessa delineação, os discentes produziram suas narrativas. Após essa etapa todos os textos foram revisados por nós e devolvidos aos seus escritores para que fizessem as reformulações propostas.

Na fase da escrita já foi possível perceber que os resultados obtidos seriam excelentes, pois os alunos não consideraram o ato apenas como mais uma atividade que deveriam fazer para obter notas, mas sabendo que os textos seriam expostos, apresentados em eventos da instituição e lançados ao público, vestiram-se de verdadeiros escritores e foram buscar elementos para seus enredos. A maioria se baseou em suas leituras prediletas, fazendo assim um exercício de intertextualidade, aliás, esse é um recurso muito comum na literatura contemporânea. Autores se baseiam em obras clássicas para, sob um novo prisma, compor os seus escritos. Podemos citar como exemplo a obra Chapeuzinho amarelo de Chico Buarque de Holanda e o poema Licença Poética de Adélia Prado. Mas também houve aqueles que optaram por retratar suas próprias vidas. Nesses casos, a realidade dos alunos serviu de base para a composição literária.

Feito isto, passou-se a revisão dos escritos para identificar se os textos estavam coesos, coerentes e se possuíam as marcas da escrita literária. Concluída essa etapa, os alunos foram orientados a reescrever os seus textos fazendo as adaptações necessárias.

De posse do texto verbal, passou-se a ilustração das narrativas. Nessa etapa, os discentes ilustraram suas histórias usando as mais variadas técnicas. Para que o trabalho ficasse parecido com uma obra publicada, solicitou-se que os alunos fizessem suas biografias e um resumo que deveria compor a contracapa da obra.

[...] elaborar um texto é uma tarefa cujo sucesso não se completa, simplesmente, pela codificação das idéias ou das informações, através de sinais gráficos. Ou seja, produzir um texto não é uma tarefa que implica apenas o ato de escrever. Não começa, portanto, quando tomamos nas mãos papel e lápis. Supõe, ao contrário, várias etapas, interdependentes e intercomplementares, que vão desde o planejamento, passando pela escrita propriamente, até o momento posterior da revisão e da escrita. (ANTUNES, 2003, p. 54).

Todas essas etapas foram importantes porque consideramos que a atividade de escrita é abrangente e exige vários estágios interligados. Também pudemos colaborar com o letramento tendo em vista o trabalho com diferentes gêneros textuais, contos, romances, biografias e resumos, sem contar a incorporação dos textos não verbais. Dessa forma, os alunos fizeram suas produções pensando em situações reais de escrita, em um público real, 
pois as produções não foram destinadas apenas à professora, mas a toda a comunidade escolar (professores, técnicos e outros alunos) e extra escolar (alunos de outros campi do Instituo Federal de Rondônia, tiveram acesso às produções).

Figura 1: Aluno produzindo a narrativa literária Figura 2: Produção de ilustraçãodo livro

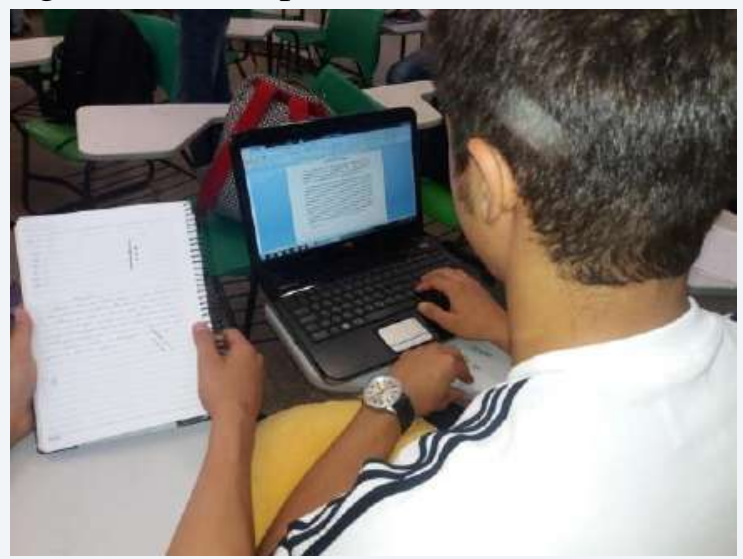

Fonte: Arquivo pessoal.

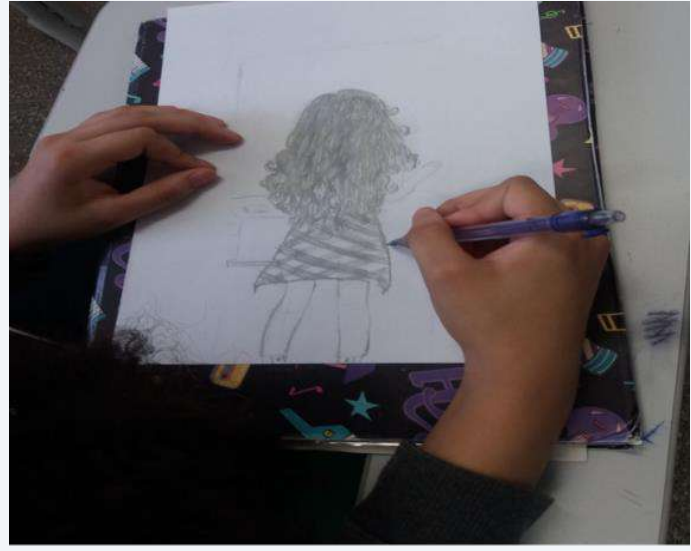

Fonte: Arquivo pessoal.

Figura 3: Algumas obras prontas

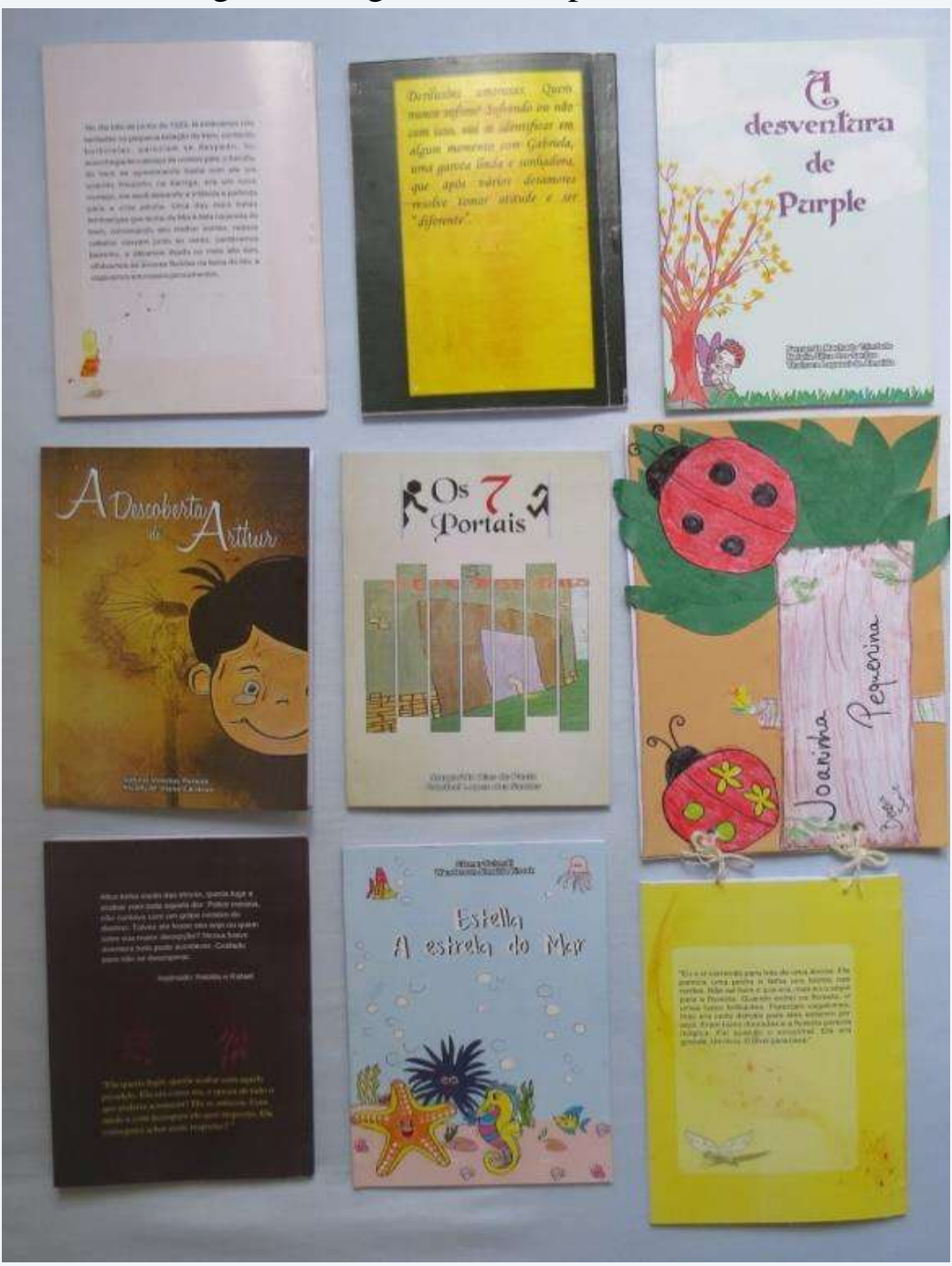


Fonte: arquivo pessoal

A experiência, considerando todo o percurso do projeto, foi importante para os alunos, pois puderam adentrar no mundo permitido apenas pela literatura e criar as mais fascinantes histórias, consoante podemos comprovar pelos relatos descritos abaixo:

A princípio eu me assustei bastante, pois nunca tinha tido a oportunidade de escrever um livro e ainda em dupla. Desde o começo tivemos um pensamento bem amplo a respeito do que o livro iria se tratar, pois como gostamos de filmes de ação, ficção e séries medievais foi tudo bem mais fácil de trabalhar. As ideias e os pensamentos foram surgindo, e nós elaboramos uma grande produção! (C. M., $1^{\circ}$ Agroecologia, 2017).

Quando o projeto foi apresentado aos alunos, muitos ficaram assustados com a ideia de ser o autor de um livro, pois nunca haviam tido essa experiência. Houve aqueles que, em um primeiro momento, sentiram-se incapazes de fazer a tarefa proposta. Entretanto, à medida que as aulas transcorriam, os encaminhamentos eram realizados e as leituras feitas, os discentes começaram a compreender a proposta e a sentirem-se motivados para realizá-la Esta deixou de ser mera ação para receber uma nota ao final do bimestre e tornou-se atividade na perspectividade Vigotskiniana, pois o motivo da realização estava interligado com a ação e o resultado esperado.

Há uma relação particular entre atividade e ação. O motivo da atividade, sendo substituída, pode passar para o objeto (o alvo) da ação, com o resultado de que a ação é transformada em uma atividade. Este é um ponto excepcionalmente importante. Esta é a maneira pela qual surgem todas as atividades e novas relações com a realidade. (LEONTIEV, 2001, p.69).

Para que houvesse a transição de ação para atividade, situações e necessidades foram criadas nos alunos, tornando-se potencializadora. É pela atividade que o sujeito melhor aprende, melhor se relaciona com o grupo social e faz com que ele seja sujeito de todo o processo.

Também é perceptível a importância do processo intertextual na composição, já que a educanda afirma ter recorridos a outros gêneros ficcionais para a produção de sua narrativa literária. Também houve os alunos que reconheceram a importância da escrita como forma de expressão pessoal e meio de objetivação da apropriação cultural:

Escrever este livro foi muito gratificante e prazeroso, pois me dediquei de corpo e alma. Além do projeto ter ajudado na escrita e nos conhecimentos, me proporcionou um alívio. Escrever abriu minha mente e me fez seguir em frente com o coração limpo e aberto. (D. V.,1º A Agropecuária, 2017). 
Escrever é ato de nos expressarmos em palavras, como afirmou a aluna, nos "alivia", pois nos signos linguísticos depositamos nossas crenças, visões, ideologias e sentimentos. Muitos alunos utilizaram esse processo de criação para se expressarem, representarem suas próprias vidas, já que muitas vezes não se sentem a vontade para fazer isso na realidade. Mas agora, por meio de um personagem ficcional, localizado em um outro espaço e tempo puderam expressar tudo o que sentiam e pensavam.

A literatura corresponde a uma necessidade universal que deve ser satisfeita sob a pena de mutilar a personalidade, por que pelo fato de dar forma aos sentimentos e a visão de mundo ela nos organiza, nos libera de caos e, portanto, nos humaniza. Negar a fruição literária é mutilar a nossa humanidade [...]. (CANDIDO, 1995, p. 186).

Pela citação acima podemos perceber a importância da literatura na constituição do sujeito. Lendo viajamos, nos identificamos com os mais distintos sentimentos, aprendemos e nos formamos. A escrita literária também pode ter todas essas funções, a de permitir o escritor, em nosso caso o aluno-autor, de constituir o seu próprio mundo, personagens, histórias, enfim exercer o seu processo criativo.

Passei 16 anos de minha vida pensando em diversas coisas (até mesmo assuntos rotineiros) que poderiam virar um livro, mas nunca parei e escrevi sobre isso. Quando a professora Andreia solicitou que escrevêssemos um livro fiquei muito empolgada! Essa foi a melhor experiência que tive. É uma admirável forma de expor ideias, pensamentos e assuntos malucos que de fato nunca acontecerão, mas poderão ser escritas e transformadas em algo material, preservando nossa imaginação. (V. B., 1º A Agropecuária, 2017).

A discente, em seu depoimento, demonstra conhecer o caráter ficcional que marcam os textos literários. $\mathrm{Na}$ atividade, ela encontrou uma forma de transgredir a realidade, elemento possível apenas nos textos literários ficcionais. Os Parâmetros Curriculares Nacionais abordam essa característica inerente à literatura:

A literatura não é cópia do real, nem puro exercício de linguagem, tampouco mera fantasia que se asilou dos sentidos do mundo e da história dos homens. Se tomada como uma maneira particular de compor o conhecimento, é necessário reconhecer que sua relação com o real é indireta. Ou seja, o plano da realidade pode ser apropriado e transgredido pelo plano do imaginário como uma instância concretamente formulada pela mediação dos signos verbais (ou mesmo não verbais conforme algumas manifestações da poesia contemporânea). (PCN, 1998, p. 37). 
O literário traz a marca da invenção e inovação. Nessa forma específica de linguagem é permitido transgredir regras tanto da escrita convencional quanto da realidade. Os signos linguísticos verbais e não verbais são utilizados de maneira artística.

Já as alunas representadas pelos discursos abaixo destacaram a criatividade envolvida durante todo o processo de composição da narrativa:

Quando a professora apresentou o projeto fiquei um pouco receosa, pois não tinha ideia de como fazer um livro. Já li vários, mas nunca tinha pensado na ideia de fazer um. Depois, com o passar do tempo, a ideia foi se esclarecendo, com o auxílio da professora, e com isso tomei gosto em escrever histórias empolgantes. Esse projeto também me auxiliou muito no processo criativo e na escrita, pois tinha que utilizá-los com muita intensidade. Ao final, ganhei um pouco de experiência além de aprender bastante. Espero que essa ação se espalhe, para outros alunos terem a mesma sensação maravilhosa do que é escrever um livro (M. P., $1^{\circ}$ ano A Agropecuária, 2017).

Ter feito uma obra literária, sem dúvida, foi uma experiência inigualável e fascinante. Sempre tive amor por livros, e ter tido a oportunidade de participar da escrita de um, foi algo encantador. Estimulou minha criatividade e aumentou minha vontade de perdurar em meio a este mar de letras. A cada linha, um pensamento. A cada página, um sorriso (N. V., $1^{\circ}$ ano Agropecuária, 2017).

As alunas compreenderam que produzir textos narrativos literários requer o uso da criatividade e imaginação. Com o projeto os discentes não apenas tiveram acesso constante à escrita, mas também puderam transgredir as regras tradicionais, haja vista a permissão encontrada na escrita de textos literários.

Quem escreve um texto literário não quer apenas dizer o mundo, mas recriálo nas palavras, de forma que, nele, importa não só o que se diz, mas também o modo como se diz. A mensagem literária é autocentrada, isto é, o autor procura recriar certos conteúdos na organização da expressão. Múltiplos recursos são usados para isso: ritmos, sonoridades, distribuição de sequências por oposições e simetrias, repetição de palavras ou de sons (rimas) etc. (SAVIOLI; FIORIN, 2006, p. 361 apud GAIGNOUX, 2014, p. $3)$.

E por meio dessa possibilidade de criação e recriação tanto da realidade quanto da linguagem, os alunos-autores puderam mostrar suas vozes, em uma perspectiva permitida apenas pela literatura. Trabalhar pelo prisma de permitir aos alunos a produção de textos que teriam uma função social, seriam lidos por outros leitores que não apenas o próprio professor, contribuiu significativamente para o desempenho da atividade. Já que a ementa dos primeiros 
anos traz a tipologia narrativa e o texto literário como conteúdos a serem trabalhados, primou pelo trabalho com sentido e cumprindo uma função social.

Para isso fez-se uso da Teoria Histórico-Cultural: “A escrita precisa responder a uma necessidade da criança, a necessidade de ler e escrever para recordar e comunicar ideias, sentimentos e conhecimentos" (VYGOTISKI, 1995, p. 184). Isso se aplica também aos adolescentes, que tiveram a necessidade de utilizar os signos linguísticos para compartilhar com leitores suas ideias, conhecimentos e sentimentos por meio da prática social de produção de livros.

O projeto foi aceito pelos alunos porque viram função no ato de escrever. Essa atividade em muito se distanciou da prática retrógrada com que muitas vezes a escrita é apresentada aos alunos: produzir um texto sem objetivos claros tendo apenas o professor como leitor/interlocutor. Dessa forma, os discentes não veem motivos para se dedicar à escrita.

Em suma, nesse trabalho os alunos tiveram a oportunidade vivenciar situações reais de escrita ao se por no lugar de autor e ainda fazer uso social do processo gráfico. Condições foram criadas para que os alunos não fossem meros receptores passivos da aprendizagem de conteúdos como: texto literário, tipologia narrativa e gêneros textuais, mas que essa aprendizagem fosse construída pelo grupo de forma ativa.

\section{Considerações finais}

Com base no exposto até aqui, podemos afirmar, conforme orientações da Teoria Histórico-cultural, que o sujeito não nasce pronto, pelo contrário, é um ser social e cultural que para o seu desenvolvimento necessita de um mediador mais experiente. Essa compreensão nos faz pensar na importância da escola e do professor no processo de humanização do sujeito, por isso a realização do projeto em pauta contribuiu para que os alunos tivessem contato com uma cultura mais elaborada como é o caso das obras literárias e com diferentes formas de linguagem (verbal, não-verbal, literária).

Os envolvidos apreenderam as marcas presentes em textos em que predominam a função poética e se apropriaram dos recursos peculiares a essa forma de escrita. Tornaram-se ainda leitores críticos ao compreenderem todo o processo envolvido na composição textual e puderam vivenciar todas as etapas presentes na vida de um escritor que se inicia na leitura de vários textos e encerra na impressão e edição das obras. A partir do processo de mediação, puderam se apropriar do conhecimento cultural pertinente à elaboração de uma obra literária. 
Pelo exposto afirmamos que as situações propostas, intervenções realizadas, a forma como o projeto foi apresentado aos alunos, motivando-os, contribuiu para a realização da atividade, pois motivos, ação e resultados esperados estavam interligados. O trabalho foi profícuo e os alunos sentiram-se motivados para a escrita literária a ponto de continuarem produzindo outros textos e até mesmo continuações para suas histórias iniciais, criando trilogias.

\section{REFERÊNCIAS}

ANTUNES, Irandé. Aula de português: encontro e interação. São Paulo: Parábola Editorial, 2003.

CANDIDO, Antonio. O direito à literatura. Vários escritos. São Paulo: Duas Cidades, 1995.

COLOMER, T. Andar entre livros: a leitura literária na escola. Tradução de Laura Sandroni. São Paulo: Global, 2007.

COLASANTI, Marina. A moça tecelã. In: Doze reis e a moça no labirinto do vento. São Paulo: Global, 2000.

COSSON, Rildo. Letramento Literário: teoria e prática. São Paulo: Contexto, 2011.

DALLA-BONA, Elisa Maria; BUFREM, Leilah Santiago. Aluno-autor: a aprendizagem da escrita nas séries iniciais do Ensino Fundamental. 2013. Disponível em:

<www.scielo.br/pdf/edur/v29n1/a09v29n1.pdf. > Acesso em: 14/11/2017.

GAIGNOUX, Aline de Azevedo. O texto literário na escola. Palimpsesto, Rio de Janeiro, n.19, out - nov. 2014, pp. 495-502. Disponível em:

<http://www.pgletras.uerj.br/palimpsesto/num19/estudos/palimpsesto19estudos07.pdf >. Acesso em: 16/ 11/. 2017.

GALVÃO, André Luiz Machado. O Ensino da Literatura do Ensino Médio: Questões sobre a formação do gosto pela leitura. s/d. Disponível em:

<www.editorarealize.com.br/.../Trabalho_Comunicacao_oral_idinscrito_20c91b4362c. Acesso em 10/12/2017>.

LEONTIEV, Alexis N. Uma contribuição à Teoria do Desenvolvimento da Psique Infantil. In: Linguagem, Desenvolvimento e Aprendizagem. São Paulo: Ícone, 2001.

MORIN, E. Amor, poesia, sabedoria. 2 ed. Rio de Janeiro: Bertrand Brasil, 1999.

PARÂMETROS CURRICULARES NACIONAIS: LÍNGUA PORTUGUESA. Brasília: 1998. Disponível em: <http://portal.mec.gov.br/seb/arquivos/pdf/portugues.pdf>. Acesso em 14 nov.2017. 
SAINT-EXUPÉRY, Antoine de. O pequeno príncipe. Rio de Janeiro, Editora Agir, 2009.

SAVELI. Esméria de Lourdes. Por uma pedagogia da leitura: reflexões sobre a formação do leitor. In: CORREA, D. A. e SALEH, P. B. O. (orgs.). Práticas de letramento no ensino: leitura, escrita e discurso. São Paulo: Parábola Editorial; Ponta Grossa, PR: UEPG, 2007.

VASCONCELOS, José Mauro de. O meu pé de laranja lima. 2.ed. São Paulo:

Melhoramento, 2005.

VYGOTSKI, Lewis. S. Laprehistoriadeldesarrollodellenguajeescrito. In.: VYGOTSKI, Lewis. S. Obras Escogidas III: Problemas del desarrollo de la psique. Madrid: Visor Distribuciones, S. A., 1995.

\section{$\underline{\text { SOBRE AS AUTORAS }}$}

\section{Andreia dos Santos Oliveira}

Professora do Instituto Federal de Rondônia. Doutoranda em Educação pela Universidade Estadual de São Paulo, Campus Júlio de Mesquita Filho, Marília. Grupo de Pesquisa Multidisciplinar em Educação e Infância - Grupo Educa. E-mail: andreia.oliveira@ ifro.edu.br

\section{Cyntia Graziella Guizelim Simões Girotto}

Doutora em Educação pela Universidade Estadual Paulista (UNESP). Livre Docente em Leitura e Escrita pela Universidade Estadual Paulista. Professora da UNESP. Grupo de Pesquisa do Centro de Estudos em Leitura e Literatura Infantil e Juvenil. E-mail: cyntia@marilia.unesp.br

\section{Juracy Machado Pacífico}

Professora da Universidade Federal de Rondônia - Programa de Pós-Graduação em Educação Escolar. Doutora em Educação pela Universidade Estadual Paulista Júlio de Mesquita Filho. Grupo de Pesquisa Multidisciplinar em Educação e Infância - Grupo Educa. E-mail: juracypacifico@unir.br 